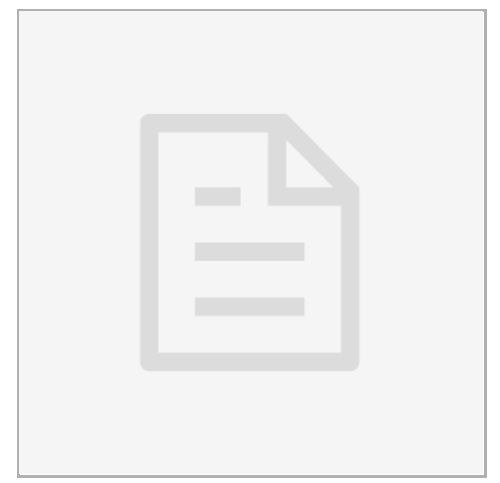

DEC 15, 2017

\section{(3) Preparation and evaluation of brain-targetd thermosensitive in situ gel of geniposide}

c] PLOS One

Yingting Wang ${ }^{1}$, Shulong Jiang ${ }^{1}$, Hongli Wang ${ }^{1}$, Haiyan Bie ${ }^{1}$

${ }^{1}$ The First People's Hospital of Jining

\section{open $\boldsymbol{\text { Access }}$}

\section{DOI:}

dx.doi.org/10.17504/protocol s.io.ks2cwge

\section{External link:}

https://doi.org/10.1371/journa l. pone.0189478

Protocol Citation: Yingting Wang, Shulong Jiang, Hongli Wang, Haiyan Bie 2017.

Preparation and evaluation of brain-targetd thermosensitive in situ gel of geniposide.

\section{protocols.io}

https://dx.doi.org/10.17504/p rotocols. io.ks2cwge

\section{MANUSCRIPT CITATION:}

Wang $\mathrm{Y}$, Jiang $\mathrm{S}$, Wang $\mathrm{H}$, Bie H (2017) A mucoadhesive, thermoreversible in situ nasal gel of geniposide for neurodegenerative diseases. PLOS ONE 12(12): e0189478. doi: 10.1371/journal. pone.018947 8

License: This is an open access protocol distributed under the terms of the Creative Commons Attribution License, which permits unrestricted use, distribution, and reproduction in any medium, provided the original author and source are credited
Jiang Shulong

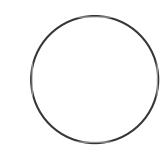

Jiang Shulong 
Created: Nov 14, 2017

Last Modified: Feb 21, 2018

PROTOCOL integer ID:

8762

Keywords: Geniposide,

Thermosensitive in situ gel,

Central Composite Design-

response Surface

Methodology, In vitro, Ex vivo

Determination of geniposide: C18 column (5 $\mu \mathrm{m}, 4.6 \mathrm{~mm} \times$.

1

Preparation of formulation: 1 Purified water was stored ove.

Clarity of formulation : Under black and white background,

The pH value of formulation was determined by using the p...

Gelation temperature of formulation: 1 Hydrogel $(0.5 \mathrm{ml}) \mathrm{w}_{\text {. }}$ 


\section{The gel strength: A sample of $50 \mathrm{~g}$ of hydrogel was put into..}

Mucoadhesive strength: 1 A section of fresh goat nasal mu...

In vitro release: 1 Cold hydrogel (5 g) was transferred into

8

Ex vivo drug permeation: 1 A section of fresh goat nasal mu. 